\title{
The Engineering Classroom is Still Relevant
}

\section{Dr. Eric J. Fitzsimmons, Kansas State University}

Dr. Fitzsimmons is an Assistant Professor in the Department of Civil Engineering at Kansas State University. He received his B.S., M.S., and Ph.D. degrees in Civil Engineering with a specialization in transportation from Iowa State University. During his graduate career, Dr. Fitzsimmons worked at the Institute for Transportation (InTrans) at Iowa State University and received training to specialize in highway safety, particularly in rural areas. Dr. Fitzsimmons worked closely with staff at the Iowa Department of Iowa (Iowa DOT) and developed many relationships with local road supervisors, and county engineers. His dissertation investigated horizontal curves and how drivers traverse through the curve by collected vehicle lateral position and speed data. The results of the dissertation found that there are distinct differences between drivers in urban areas and rural areas when traversing a curve. Through the research he assisted with, Dr. Fitzsimmons has made a substantial impact to roadway safety in both rural and urban areas. Dr. Fitzsimmons continued his highway safety work as a Post- Doctoral Researcher at the University of Kansas where he worked with the Kansas Department of Transportation on research to improve road safety in both urban and rural areas, specifically investigating low-cost countermeasures, crash analyses, and work zone safety. Dr. Fitzsimmons was award two FHWA Dwight D. Eisenhower Fellowships. He also won regional and local awards through the Institute of Transportation Engineers. Dr. Fitzsimmons is a member of the Transportation Research Board's standing committees on Traffic Law Enforcement (ANB40), Operational Effects of Geometrics (AHB65), and Access Management (ANB70).

\section{Dr. Stacey E. Tucker-Kulesza, Kansas State University}

Dr. Stacey Tucker-Kulesza is an assistant professor in the civil engineering department at Kansas State University. Dr. Tucker-Kulesza is a graduate of the American Society of Civil Engineers Excellence in Civil Engineering Education (ExCEED) program. She teaches undergraduate and graduate courses in geotechnical engineering.

\section{Mr. Xiongya Li, Kansas State University}

Xiongya Li was born in Dalian, China. He received the B.S. degree in mathematics and economics from the Emporia State University, Kansas. Now he is Ph.D. candidate in statistics at Kansas State University. He joined the department of statistics in 2013 and became a graduate teaching assistant. He has also been a graduate research assistant in the summer of 2014 and summer of 2015. His current research interests include measurement error models, robust Laplace distribution, variable selection in high dimensional data and count data. He is also a member of American Statistical Association. He was the recipient of the Howard Siepman Memorial Scholarship, Statistics Graduate Resesearch Scholarship, and U.S. Mathematical Contest in Modeling Competition as meritorious winner.

\section{Whitney Jeter, Fort Hays State University}

Whitney Jeter is a social psychologist. She received her $\mathrm{PhD}$ from Kansas State University and currently serves as an Assistant Professor at Fort Hays State University. She teaches a variety of classes including general psychology, social psychology, and personality.

\section{Dr. Jana R. Fallin, Kansas State Univesity Teaching \& Learning Center}

Jana Fallin is Director of the Teaching \& Learning Center at Kansas State University. She received the highest teaching award at the University, the Coffman Chair of the University Distinguished Teaching Scholars, in 2002. She is a professor in music, with degrees from Baylor University and the University of Texas at Austin. 


\section{THE ENGINEERING CLASSROOM IS STILL RELEVANT}

Abstract

Attrition in engineering is a complex issue with dynamically linked variables related to teaching methods in the classroom, student learning behaviors, and student perceptions of difficult material. Extensive research has been conducted in order to understand common, yet ineffective teaching practices in engineering that result in the loss of numerous future engineers. The objective of this study was to determine student actions necessary to achieve a desired grade in any engineering course, regardless of course delivery method and instructor effectiveness in the classroom. An anonymous survey was disseminated and logistic regression models were developed in order to determine relationships between self-regulated learning behaviors and final grades in seven freshman to senior engineering classes taught by civil engineering faculty. A total of five prediction models were developed for each letter grade, with the failing grade " $F$ " serving as the baseline condition, or null model. The models found three significant variables that affect a student's final grade: regular class attendance, note-taking during class, and if he or she could keep up with the instructor during lecture. These interactive learning behaviors were all identified as critical for success, defining success as receiving an " $\mathrm{A}$ " in an engineering course. The combination of students taking notes and attending class showed the highest probability of a student receiving an "A." Results of this study have been summarized into a graphic that the authors show and discuss during the first class with students. This powerful graphic shows students what they can do in classes of all levels of civil engineering to succeed in their ever-changing learning environment.

Introduction

As the need for engineers increases, retention of undergraduate engineering students is essential ${ }^{1}$. The Kansas legislature recently passed the University Engineering Initiative Act in an attempt to increase the number of engineering graduates statewide, thereby increasing the number of engineering graduates at Kansas State University (K-State) by $60 \%$ over a ten-year period ${ }^{2}$. In addition, the President's Council of Advisors on Science and Technology (PCAST) developed a report that calls for "one million additional college graduates with bachelor or associate degrees

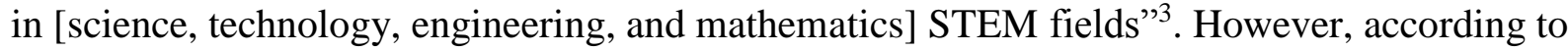
the National Research Council, many undergraduate engineering programs fail to attract and retain students in engineering ${ }^{4}$. Ohland et al. found that $93 \%$ of engineering students enrolled in engineering courses after eight semesters had declared themselves engineering majors as freshman, thus highlighting the need for retention because freshman non-engineering students are unlikely to transfer into engineering ${ }^{5}$. Once in the college, often engineering students are not retained because of poor grades ${ }^{6}$ or a perceived inability to maintain pace with the curriculum ${ }^{7}$. This study assessed in-class behavior of students in freshman- to senior-level civil engineering courses and related in-class behavior predictors to final grades.

As the demand for engineering student retention increases, researchers have advocated improved teaching practices in engineering classrooms ${ }^{8}$. Jain, Shanahan, and Roe found that deans of engineering schools attribute ineffective teaching as the most significant reason for attrition in engineering ${ }^{9}$. The common assumption that good researchers are inherently good instructors continues to be disproven ${ }^{10,11}$ yet most engineering professors, particularly in research institutions such as K-State, receive no formal training in teaching. These professors often rely 
heavily on the traditional lecture style that can be ineffective and disadvantageous to students of certain learning styles ${ }^{12,13}$. Smith, Irey, and McCaulley advocated a need for a wide range of learning activities in the classroom in order to accommodate a diverse array of learning styles ${ }^{14}$. A learning style is the "characteristic cognitive, affective, and psychological behaviors that serve as relatively stable indicators of how learners perceive, interact with, and respond to the learning environment"15. Although in our experience most professors want to excel at teaching, tenure and promotion reviews often are driven more by research productivity than teaching. Therefore, we seek to understand successful student actions across many teaching styles in order to correlate success and final grades. There is a need to inform students of how to succeed under teaching styles that do not necessarily accommodate their individual learning styles. Following this introduction, the study focus and research background are described. The empirical setting is also discussed, followed by analysis methodology and results. The paper concludes with the graphic summarizing the findings of the study that is showed to students at the beginning of each semester and a final discussion.

Focus of the Study

This study focused on student behavior in six civil engineering classes and one construction science class. These seven classes, taught by one of five civil engineering professors, were taken by freshman to senior, primarily engineering, students. The survey was utilized to understand what actions students take in order to be successful in their classes, regardless of the instructor or the instructor's teaching style. Several researchers have investigated student success related to learning style and preferential presentation from an instructor in conjunction with student learning styles ${ }^{13,16-18}$. However, Wankat and Oreovicz found that, regardless of a student's learning style or intelligence, motivation fundamentally controls whether or not a student learns ${ }^{19}$. Similarly, Castiglia noted that "academic success, in part, derives from students' study habits - which, in turn, are driven by students' motivations" 20 . A primary finding of this study correlated with student motivation and how this motivation affects a student's final grade independent of the corresponding course.

\section{Survey Development}

An electronic survey was developed based on a review of relevant literature and similar surveys $^{21}$ as well as the help of the Center for Teaching and Learning at K-State. The survey targeted seven classes at the K-State main campus associated with topics relating to civil engineering. The justification for selecting seven classes was to develop a potential pool of respondents that represented students at various stages of the engineering program. Students enrolled in these classes were primarily civil engineer majors; the rest of the students were from various engineering departments and other STEM-related fields. The survey was organized according to the following research questions:

1) How do students prepare for class?

2) How do students prepare for exams?

3) Is there a universal correlation between student preparation and final grades regardless of the instructor or student background?

The electronic survey was divided into two sections. The first section related to student background, including student ID, which current classes they were currently enrolled in while taking the survey, major, gender, military or veteran status, children, and home town. The second 
section was designed to help answer the research questions. These questions and the response type are shown in Table 1.

TABLE 1 Section 2* Questions of the Student Survey

\begin{tabular}{l|l|l}
\hline $\begin{array}{l}\text { Question } \\
\text { Number }\end{array}$ & Question & $\begin{array}{l}\text { Response } \\
\text { Type }\end{array}$ \\
\hline 10 & For this class, was a textbook purchased, rented, or borrowed? & Categorical \\
\hline 11 & $\begin{array}{l}\text { How often did you attend lecture (not including sick days or excused } \\
\text { absences)? }\end{array}$ & Categorical \\
\hline 12 & How did you prepare for lecture? & Multiple \\
\hline 13 & $\begin{array}{l}\text { After lecture, you were assigned either homework, a project, or reading. } \\
\text { When do you typically complete this? }\end{array}$ & Multiple \\
\hline 14 & $\begin{array}{l}\text { If you were assigned homework problems that required multiple steps to } \\
\text { solve, how did you approach the problem? }\end{array}$ & Multiple \\
\hline 15 & $\begin{array}{l}\text { During lecture, are you able to take notes, keep up with the instructor, and } \\
\text { understand the concepts? }\end{array}$ & Categorical \\
\hline 16 & $\begin{array}{l}\text { What way is more beneficial for you to learn a concept that requires } \\
\text { multiple steps to solve a problem during lecture? }\end{array}$ & Multiple \\
\hline 17 & How do you study for this class? & Multiple \\
\hline 18 & When I don't understand a concept during lecture or after lecture? & Multiple \\
\hline 19 & An exam, midterm, or final is approaching? & Multiple \\
\hline
\end{tabular}

*Note: Section 1 included student background information.

As shown in Table 1, students were given the opportunity to select multiple responses for questions where we believed a combination of strategies exist. During development of the survey questions, we did not examine possible correlation among questions or the number of responses per question.

\section{Data Collection Protocol}

Prior to distribution of the electronic survey, we received permission from the registrar's office to use final grades and student IDs. We also received approval from K-State's Internal Review Board (IRB) in order to ensure minimal risks and appropriate safeguards were in place. The electronic survey was conducted through Qualtrics ${ }^{22}$, a secure surveying service. The class professors were asked to distribute web links to students with the assurance that student IDs were only used to match final grades. Survey instructions also stated that the survey would close on a certain date and that survey information would not be compiled until final grades were submitted. Students were able to take the electronic survey in December 2014, and the information was compiled in February 2015. Student identifiers were removed from the dataset once grades to responses were matched and verified.

\section{Data Reduction Process/Data Description}

A total of 401 students completed the survey however, many students provided false student IDs or failed to answer any questions. Responses with either of those characteristics were eliminated from consideration. Therefore, a total of 374 survey responses were used for analysis.

Descriptive statistics of Section 1 of the survey (student demographics) are shown in Table 2. The significantly higher percentage of males than female students is typical of engineering programs, with only $19.2 \%$ of bachelor's degrees awarded nationwide to women ${ }^{23}$. Military status was included as a demographic because of the number of K-State students in the military 
due to the proximity of Fort Riley, a large military installation. The high percentage of in-state students shown in the table is consistent with K-State demographics.

TABLE 2 Survey Respondent Demographics

\begin{tabular}{l|l|l}
\hline Response & Number of Responses & Percent Responses \\
\hline Male & 317 & $85 \%$ \\
Female & 57 & $15 \%$ \\
\hline Active Military & 11 & $3 \%$ \\
Military Veteran & 9 & $2 \%$ \\
\hline Student with Children & 7 & $2 \%$ \\
\hline In-State Native & 292 & $78 \%$ \\
Out of State & 55 & $15 \%$ \\
Out of Country & 27 & $7 \%$ \\
\hline
\end{tabular}

Final grade distributions for the 374 students are shown in Figure 1. The classes in this study were freshman- to senior-level civil (CE) and construction science (CNS) classes, including CE 101 Introduction to Civil Engineering, CE 212 Elementary Surveying, CNS 231 Statics A, CE 333 Statics, CE 530 Statics and Dynamics, CE 533 Mechanics of Materials, and CE 522 Soil Mechanics. Construction science students typically take CNS 231, which does not require math beyond Calculus I. The alternate Statics course, CE 333, requires Calculus II and is requires for architectural engineering ( $\mathrm{AE}), \mathrm{CE}$, and Mechanical Engineering (ME) students. CE 212 is required for $\mathrm{CE}, \mathrm{CNS}$, and $\mathrm{AE}$ students, but students in other engineering disciplines and STEM students commonly take CE 212 and CE 333 as electives. CE 533 is required for AE, CE, and ME students, and CE 522 is required for all CE and AE students. CE 530 is an optional technical elective for all engineering students. Class sizes in this study ranged between 50 and 200 students. Effects of class size on final grades were not included in the model.

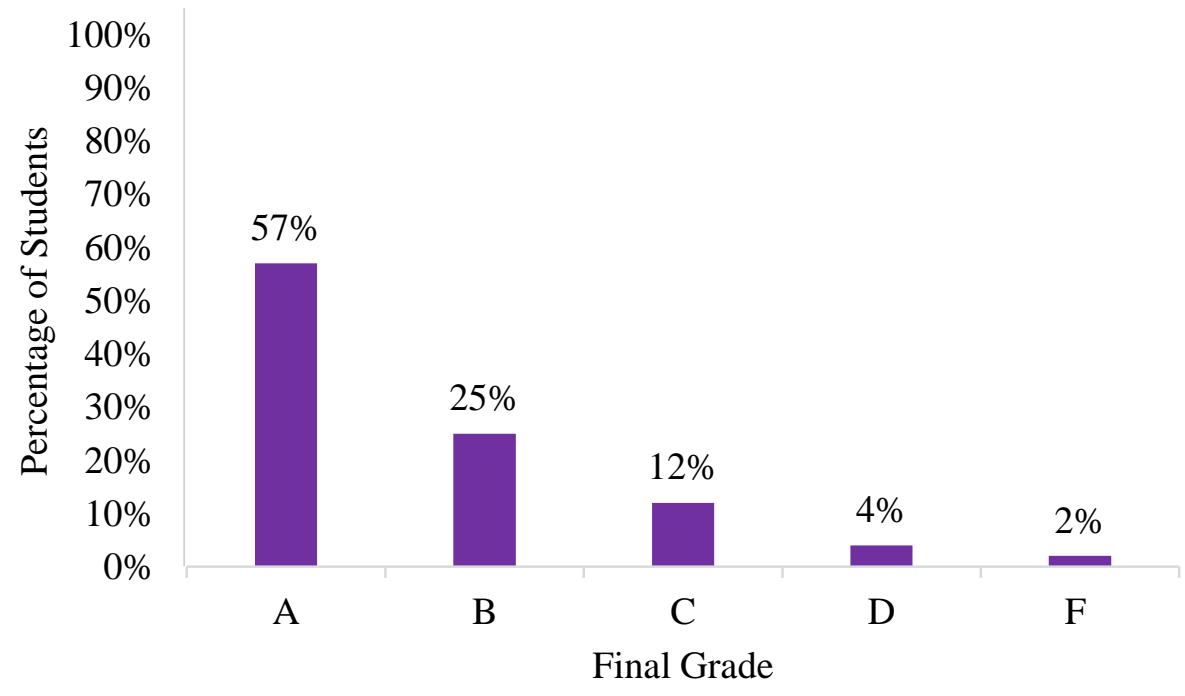

FIGURE 1 Final grade and percentage of all grades by student respondents

Fifty seven percent of the students that took the survey earned an A in the classes. This is attributed to the level of difficulty between the courses as well as the fact that some courses were taken as electives. Other variations between courses included the amount of time and effort 
required of students, required labs, writing intensive courses requiring detailed reports, and group projects. In addition, some of these classes were taught as traditional lectures that utilized PowerPoint with printed slides provided to students, whereas other classes required students to take notes during class.

Analysis Methodology

We had a rich dataset of variables and responses from students relating to their final grades. The goal of the study was to develop a model to identify significant variables (or survey questions) that related to a student's final grade and the probability of a student receiving a certain final grade if he or she utilized self-regulated learning behaviors described in the questions. In order to determine if a relationship existed, a regression model was initially used in which survey questions, or independent variables, related to the student's final grade, or ordinary dependent variable. Single response questions where analyzed first by an ordinal logistic model. For multiple response questions, multiple Chi-squared test were used to determine significant questions that had multiple responses.

An ordinal logistic model, which is a form of a generalized linear model, was selected because both the dependent and independent variables were categorical. Dummy variables were used as independent variables with a value of either 1 or 0 , "yes" or "otherwise." The basic form of the model is

$$
\operatorname{Logit}\left(P_{i}\right)=\operatorname{LN}\left(\frac{P_{i}}{1-P_{i}}\right)=\alpha_{i}+\beta_{1} X_{1, i}+\beta_{2} X_{2, i}+\cdots+\beta_{K} X_{K, i}
$$

where $P_{i}$ is binomial probabilities, $\alpha_{i}$ is model intercept, and $\beta_{1} \ldots, \beta_{K}$ are unknown estimates corresponding to independent dummy variables $X_{1, i} \ldots, X_{K, i}$. A $95 \%$ level of confidence was selected in order to determine statistically significant independent dummy variables. The student's final grade was assigned a value for the ordinary dependent variable; $\mathrm{A}=1, \mathrm{~B}=2, \mathrm{C}=$ $3, \mathrm{D}=4$, and $\mathrm{F}$ served as the baseline condition. The K-State College of Engineering does not use plus/minus grades, so those grades were not considered a possible outcome. The commercially available statistical software package SAS was used to evaluate the data, including possible interactions between independent dummy variables, using the procedure PROC

LOGISITIC that utilized a forward selection procedure, adding one predictor for each iteration of the model.

As shown in Table 3, three questions from the survey were found to be significant: Questions 11, 12, and 15. Each survey question required students to select from three or four possible answers. Questions 11 and 15 instructed students to select only one answer, while Question 12 instructed students choose answers that most appropriately described their lecture preparation, thereby creating nine possible combinations. The logistic model found that Question 15 was the only significant variable in the survey. Each of the three independent dummy variables ("yes", "no", "sometimes", and "never") were tested; "yes" was found to be significant when "never" was used as the baseline condition. Therefore, responses for the remaining three categories ("no", "sometimes", and "never") were combined, creating a dummy variable "yes the student is able to keep up" and "otherwise." This variable was a significant independent variable given the name "Keep Up." The "otherwise" portion of the dummy variable included "sometimes," thereby 
indicating that a student may sometimes be able to keep up but was included with students that could not or never keep up.

TABLE 3 Survey Questions Found to be Significant

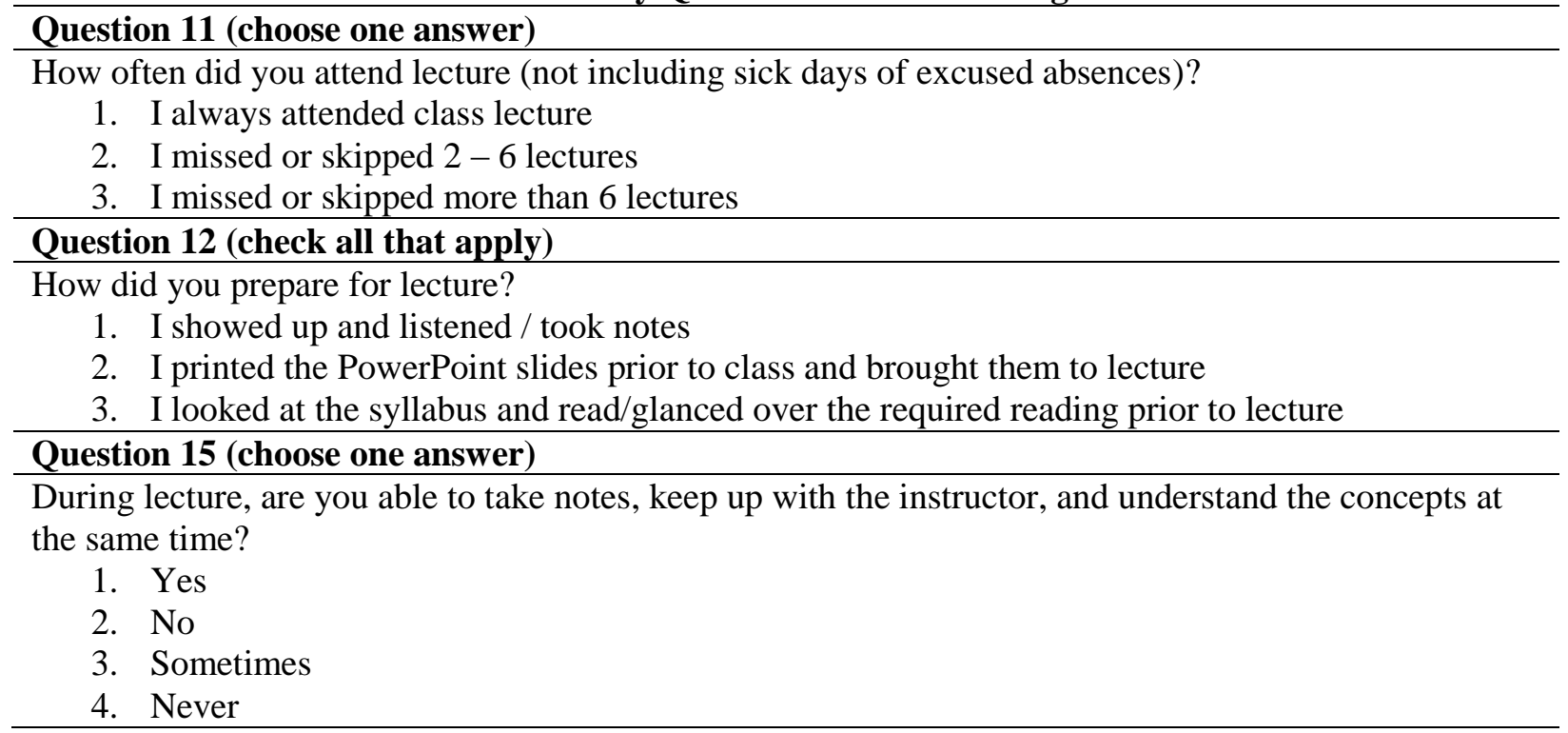

Including Question 15 or "keep up" in the logistic model, Question 11 to be the next significant categorical variable. A methodology similar to the process described for Question 15 was performed with "I missed or skipped more than 6 lectures," as the baseline condition. Three dummy variables were created. When all three dummy variables were tested, "I always attended class lecture" was found to be significant; the two remaining dummy variables were not significant. Responses for Questions 2 and 3 were combined and the dummy variable for Question 11 was tested by either a student "always attended class lecture" or "otherwise". Results showed that class attendance was a significant independent variable that was given the name "Attend."

Including Questions 11 and 15, Question 12 was the next significant multiple response variable found to be significant using a Chi-Squared test. As mentioned, students were given the opportunity to respond to more than one answer, thereby creating nine possible combinations. Each of the nine combinations was a dummy variable that was evaluated individually. Some combinations had a high number of responses. For example, 50 students responded "I showed up and listened/took notes" and "I looked at the syllabus and read/glanced over the required reading prior to lecture," while only eight students responded "I looked at the syllabus and read/glanced over the required reading prior to lecture." Because many combinations had very few responses, a total of four combinations were evaluated in which a dummy variable was created for each combination. Results showed that only a single combination was statistically significant when a student only indicated "I showed up and listened/took notes." This combination was added to the model and all remaining combinations were retested. Results showed that no other combination was significant, and the dummy variable was created where students "showed up and listened/took notes" or "otherwise." This significant independent variable was given the name "Notes." 
Analysis Results

A single logistic model was developed to predict five possible letter grades, with the failing grade "F" serving as the baseline condition. When the three variables were used to develop the logistic regressions, SAS found only one significant interaction between the variables "Keep Up" and "Attend" at a 95\% level of significance. The general form of all of the models is

$$
L N\left(\frac{P_{i}}{1-P_{i}}\right)=\alpha_{i}+\beta_{1}(\text { Keep Up })+\beta_{2}(\text { Attend })+\beta_{3}(\text { Keep Up*Attend })+\beta_{4}(\text { Notes })
$$

The developed logistic model included an intercept, or $\alpha_{i}$, which differed for each letter grade. The intercept for each model, independent variable estimates, standard errors, Wald's ChiSquared, degrees of freedom, and $p$-values are shown in Table 4. All four models (including the null model) ran parallel to each other since the same independent variables were found to be significant. The four independent variables shown in Table 4 were tested using the Wald ChiSquared statistic, resulting in $p$-values less than 0.05 for all variables, thereby indicating that they are appropriate predictors at the $95 \%$ level of significance. In order to test the basic form of the developed model (Equation 2), that a student's final grade is an "F" for failing the class, the SAS procedure PROC LOGISTIC provided three tests, as shown in Table 5: the likelihood ratio test, the score test, and the Wald test. As shown in the table, the basic form of the developed model was an improvement over the null model because independent dummy variables were added based on the $p$-values being less than 0.05. Finally, a pseudo R-squared was calculated and found to be 0.7519 , indicating that the basic form of the developed model could be explained by the significant independent dummy variables.

TABLE 4 Final Grade Prediction Models and Significant Predictors

\begin{tabular}{l|l|l|l|l|l}
\hline $\begin{array}{l}\text { Intercepts / Independent } \\
\text { Variables }\end{array}$ & $\begin{array}{l}\text { Estimate } \\
(\boldsymbol{\beta})\end{array}$ & $\begin{array}{l}\text { Standard } \\
\text { Error }(\boldsymbol{\beta})\end{array}$ & Wald's $\mathbf{X}^{\mathbf{2}}$ & $\boldsymbol{d f}$ & p-value \\
\hline Intercept (A grade) & -2.3510 & 0.6216 & 14.3023 & 1 & 0.0002 \\
\hline Intercept (B grade) & -0.9679 & 0.6110 & 2.5096 & 1 & 0.1132 \\
\hline Intercept (C grade) & 0.4030 & 0.6044 & 0.4445 & 1 & 0.5050 \\
\hline Intercept (D grade) & 1.8149 & 0.6752 & 7.2244 & 1 & 0.0072 \\
\hline Keep Up & 2.5776 & 0.7189 & 12.8539 & 1 & 0.0003 \\
\hline Attendance & 2.9733 & 0.7569 & 15.4301 & 1 & $<0.0001$ \\
\hline Keep Up*Attendance) & -2.7750 & 0.8839 & 9.8569 & 1 & 0.0017 \\
\hline Notes & 1.3989 & 0.6639 & 4.4404 & 1 & 0.0351 \\
\hline
\end{tabular}

TABLE 5 Overall Model Evaluation

\begin{tabular}{l|l|l|l}
\hline Test & $\mathbf{X}^{\mathbf{2}}$ & $\boldsymbol{d} \boldsymbol{f}$ & $\mathbf{p}$-value \\
\hline Likelihood ratio test & 44.5992 & 7 & $<0.0001$ \\
\hline Score test & 43.8054 & 7 & $<0.0001$ \\
\hline Wald test & 42.8690 & 7 & $<0.0001$ \\
\hline
\end{tabular}

Model Application and Discussion

Four independent variables were found to be significant in this study based on the survey conducted, which are expected to contribute to student success in engineering classes. The variables were "Attend," "Notes," "Keep Up," and the interaction between "Keep Up" and "Attend" if both variables were exhibited. The central mathematical concept of using a logistic 
regression is to understand the odds, or probability, of an outcome occurring. In this study, the probability of a student receiving a certain letter grade was based on the models developed. The probability for a student to obtain a certain grade depended on which learning behavior the student chose to utilize. Probabilities and variables are shown in Table 6. As shown in the table, a combination of positive student learning behaviors resulted in a greater probability that a student would earn a high grade in an engineering class.

TABLE 6 Final Grade Probabilities Based on Logistic Models

\begin{tabular}{l|lllll}
\hline \multirow{2}{*}{ Significant Variables Exhibited by Student } & \multicolumn{7}{|l}{ Final Grade Probabilities } & \\
& A & B & C & D & F \\
\hline Attend + Notes & $88 \%$ & $9 \%$ & $2 \%$ & $0.2 \%$ & $0.3 \%$ \\
Keep Up + Attend + Notes & $86 \%$ & $10 \%$ & $3 \%$ & $0.7 \%$ & $0.3 \%$ \\
Keep Up + Notes & $84 \%$ & $11 \%$ & $4 \%$ & $0.6 \%$ & $0.4 \%$ \\
Attend & $65 \%$ & $23 \%$ & $9 \%$ & $2 \%$ & $1 \%$ \\
Keep Up + Attend & $60 \%$ & $26 \%$ & $10 \%$ & $3 \%$ & $1 \%$ \\
Keep Up & $56 \%$ & $27 \%$ & $12 \%$ & $4 \%$ & $1 \%$ \\
Notes & $28 \%$ & $33 \%$ & $25 \%$ & $10 \%$ & $4 \%$ \\
No Variables Exhibited & $9 \%$ & $19 \%$ & $32 \%$ & $26 \%$ & $14 \%$ \\
\hline
\end{tabular}

Although these results may be skewed by the high percentage of "As" in the study, instructors can utilize this model in a variety of ways. This study identified three positive, dynamically linked learning behaviors that are all critical for success, defining success as receiving an " $A$ " in an engineering course. The combination of students taking notes and attending class showed the highest probability of a student receiving an "A." However, attending class and keeping up with the instructor without taking notes also showed a high probability for a student to receive an "A." This finding reinforces the need for students to attend engineering classes on a regular basis and encourages student note-taking. This is in agreement with literature showing that students who take notes in class do better on tests than those who only listen ${ }^{24-26}$.

If a student elects to utilize all significant variables in a class, the probability of that student receiving an " $\mathrm{A}$ " is $85.3 \%$ higher than the probability that the student will receive a " $\mathrm{D}$," which would require the student to retake the class according to the K-State College of Engineering policy. Although a student may fail to utilize any of the identified variables in the class and still receive an "A," the probability drops by $77 \%$. Similarly, as shown in the last row of Table 6, when no variables are utilized, the probability of receiving a lower grade increases from " $\mathrm{A}$ " to " $C$ " and decreases for " $D$ " and "F." The decrease is likely skewed due to the limited number of "D" and "F" students who participated in the survey.

The main product of this study was the development of a graphic that can be shown on the first day to students either as a projected slide or as a classroom handout. As with many faculty, we typically give an overview of our courses on the first day and discuss why this course is important for student's careers. The graphic shown in Figure 2 is included in this course overview presentation each semester to discuss how to be successful in our classes, defining success as an "A." Note that the probabilities of receiving a " $D$ " and " $F$ " were combined on the pie charts because the individual percentages were too low to be visible on the pie chart and because both grades require a student to retake the course. 

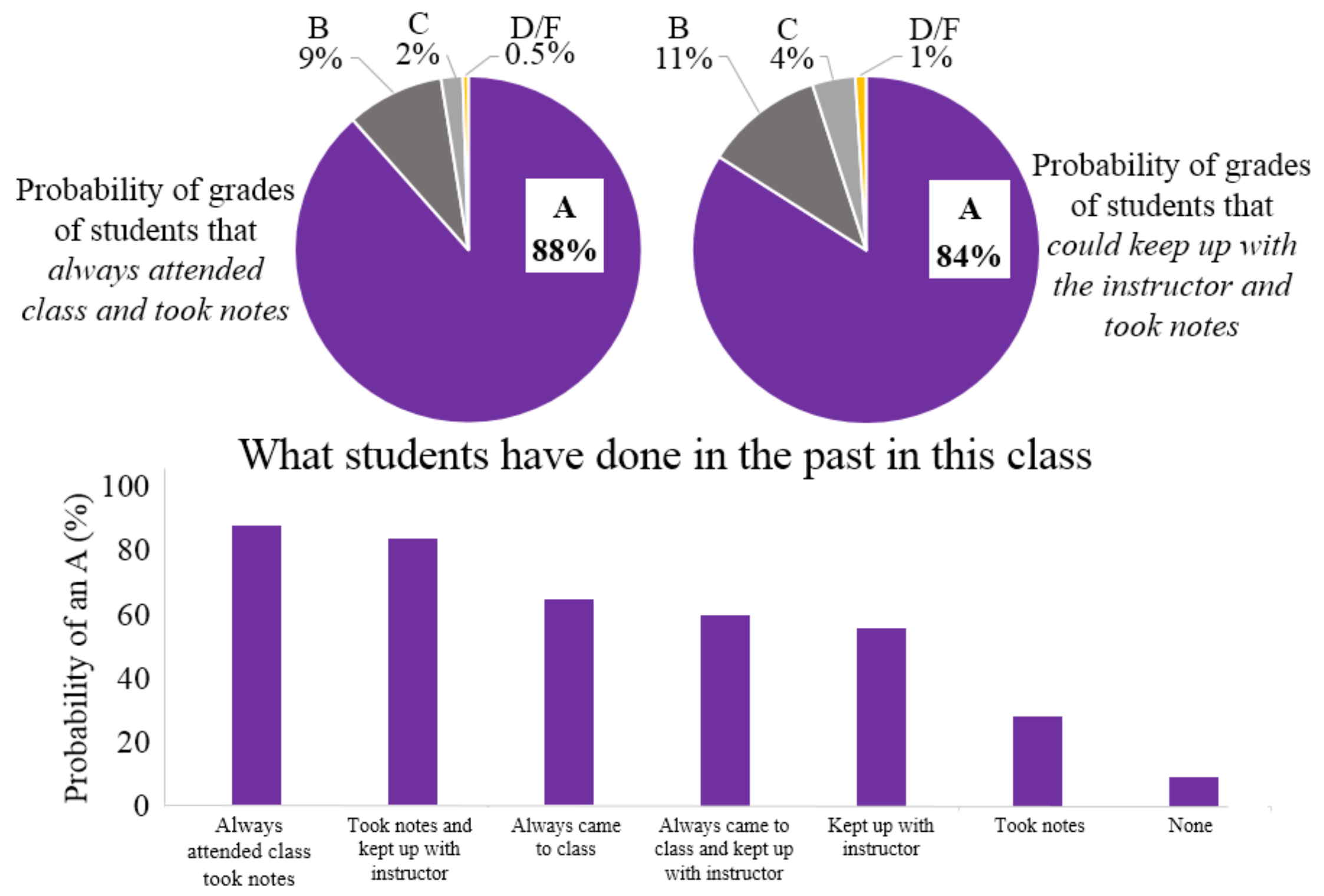

FIGURE 2 Handout that summarizes research findings for future students 
Conclusions

The pie charts in Figure 2 highlight that if students always attend class and take notes or if students can keep up with the instructor and take notes when in class that their probability of receiving an " $\mathrm{A}$ " is over $80 \%$. With the pie charts we stress the importance of using at least two identified variables. The bar chart summarizes the same information but also shows if a student elects to only utilize one critical variable the most crucial is to always attend class. It may seem obvious to instructors that, yes, it is important for students to regularly attend class, however all instructors know that some students do not regularly attend. Instructors can incorporate our findings into their classrooms by repeatedly stressing the importance of class attendance.

As mentioned, this study was limited because of sample size and skewed data. However, the data skew was expected based on courses involved in the study. The study was also limited due to the class types involved with only one course listed as an upper level engineering course. We plan to conduct similar studies in which we investigate the role of class level (i.e., freshman and sophomore classes versus junior and senior), major, and historically underrepresented groups, such as women and minorities. This preliminary study resulted in the development of a resource that instructors can hand out or show their students on the first day. Ultimately, in a field often driven by numbers, there is great power in showing engineering students that, mathematically, their academic success depends on consistent class attendance, diligent note-taking, and keeping up with the instructor during class.

References

1. Hall, C. W., Kauffmann, P. J, Wuensch, K. L., Swart, W. E., DeUrquidi, K. A., Griffin, O. H., \& Duncan, C. S. Attitude and Personality Traits in Retention of Engineering Students. Journal of Engineering Education, Vol. 104, No. 2, 2015, pp. 167-188.

2. University Engineering Initiative Act of 2011, Pub L. No. 109, § 2; July 1, 2011. http://www.kslegislature.org/li_2012/b2011_12/statute/076_000_0000_chapter/076_007_0000_article/076 _007_0137_section/076_007_0137_k/, Accessed June 10, 2015.

3. President's Council of Advisors on Science and Technology (PCAST). Engage to Excel: Producing One Million Additional College Graduates with Degrees in Science, Technology, Engineering, and Mathematics, 2012. https://www.whitehouse.gov/sites/default/files/microsites/ostp/pcast-engage-to-excelfinal_feb.pdf, Accessed June 10, 2015.

4. National Science Foundation. Women, Minorities, and Persons with Disabilities in Science and Engineering. Arlington, VA: NSF 15-311, 2015. http://www.nsf.gov/statistics/2015/nsf15311/, Accessed June 11, 2015.

5. Ohland, M.W., Sheppard, S.D., Lichtenstein, G., Eris, O., Chachra, D., \& Layton, R.A. (2008). Persistence, Engagement, and Migration in Engineering Programs. Journal of Engineering Education, Vol. 97 No. 3, 2008, pp. 259-278.

6. French, B., Immekus, J., \& Oakes, W. An Examination of Indicators of Engineering Students' Success and Persistence. Journal of Engineering Education, Vol. 94 No. 3, 2005, pp. 413-422.

7. Sax, L.J. The Gender Gap in College: Maximizing the Developmental Potential of Women and Men. Jossey-Bass, San Francisco, CA, 2008.

8. Finelli, C.J., Daly, S.R., and Richardson, K.M. Bridging the Research-to-Practice Gap: Designing an Institutional Change Plan Using Local Evidence. Journal of Engineering Education, Vol 103 No. 2, 2014, pp. 331-361. 
9. Jain, R. Shanahan, B., \& Roe, C. Broadening the Appeal of Engineering - Addressing Factors Contributing to Low Appeal and High Attrition. International Journal of Engineering Education, Vol 25 No. 3, 2009, pp 405-418.

10. Feldman, K. A. Research Productivity and Scholarly Accomplishment of College Teachers as Related to their Instructional Effectiveness: A Review and Exploration. Research in Higher Education, Vol. 26 No. 3 , 1987 pp. 227-298.

11. Terenzini, P. T. \& Pascarella, E. T. Living with Myths: Undergraduate Education in America. Change, Vol 26 No. 1, 1994, pp. 28-32.

12. Hora, M.T., Ferrare, J., \& Oleson, A. Findings from Classroom Observations of 58 Math and Science

Faculty. Wisconsin Center for Education Research, Madison, WI: University of Wisconsin-Madison, 2012.

13. Bernold, L., Spurlin, J., \& Anson, C. Understanding Our Students: A longitudinal Study of Success and Failure in Engineering with Implications for Increased Retention. Journal of Engineering Education, Vol. 96 No. 3, 2007 pp 263-274.

14. Smith, A.B., Irey, R.K., \& McCaulley, M.H. Self-Paced Instruction and College Student Personalities. Engineering Education, Vol. 63, No. 6, 1973, pp 435-440.

15. Keefe, J.W. Learning Style: An Overview, Student Learning Styles: Diagnosing and Prescribing Programs. National Association of Secondary School Principals, Reston, VA, 1979.

16. Felder, R.M. \& Brent, R. Understanding Student Differences. Journal of Engineering Education, Vol. 94, No. 1, 2005, pp. 57-72.

17. Recabarren, M., Alvarez, C., \& Diaz, M.I. Modifying the Student's Resistance Towards Active Learning with More Active Learning. Proceedings of the 122 ${ }^{\text {nd }}$ ASEE Annual Conference \& Exposition, June 14-17, Seattle, WA, 2015.

18. McCaulley, M. Psychological Types in Engineering: Implications for Teaching. Engineering Education, Vol. 66, No. 7, 1976, pp. 729-736.

19. Wankat, P.C., \& Oreovicz, F.S. Teaching Engineering. McGraw-Hill, .New York, 1993.

20. Castiglia, B. Factors Driving Student Motivation. Journal of the Academy of Business Education, Vol 7, 2006. http://abeweb.org/proceedings/proceedings06/astiglia.pdf, Accessed June 11, 2015.

21. Suresh, R. (2006). The Relationship between Barrier Courses and Persistence in Engineering. Journal of College Student Retention: Research, Theory, \& Practice, Vol. 8, No. 2, 2006, pp. 215-239.

22. Qualtrics. Qualtrics research suite, (Version 56791) [Software], 2014. http://www.qualtrics.com, Accessed February 11, 2014.

23. National Research Council. Monitoring Progress toward Successful K-12 STEM Education: A Nation Advancing? National Academies Press, Washington, DC, 2012.

24. Armbruster, B. (2009). Notetaking from Lectures. In R. F. Flippo and D. C. Caverly (Eds.), Handbook of College Reading and Study Strategy Research (2nd ed.), Routledge, New York, 2009, pp. 220-248.

25. Fisher, J. L., and Harris, M. B. Effect of note-taking and review on recall. Journal of Educational Psychology, Vol. 65, No. 3, 1973, pp. 321-325.

26. Kiewra, K. A., \& Benton, S. L. The Relationship between Information Processing Ability and Notetaking. Contemporary Educational Psychology, Vol. 13, No. 1, 1988, pp. 33-44. 